\title{
An Overview of Welfare vs Environmental Impairment: A Sociological Appraisal
}

\author{
Mohammad Taghi Sheykhi* \\ Professor Emeritus of Sociology, Alzahra University, Tehran, Iran \\ *Corresponding author: Mohammad Taghi Sheykhi, Professor Emeritus of Sociology, Alzahra University, Tehran, Iran
}

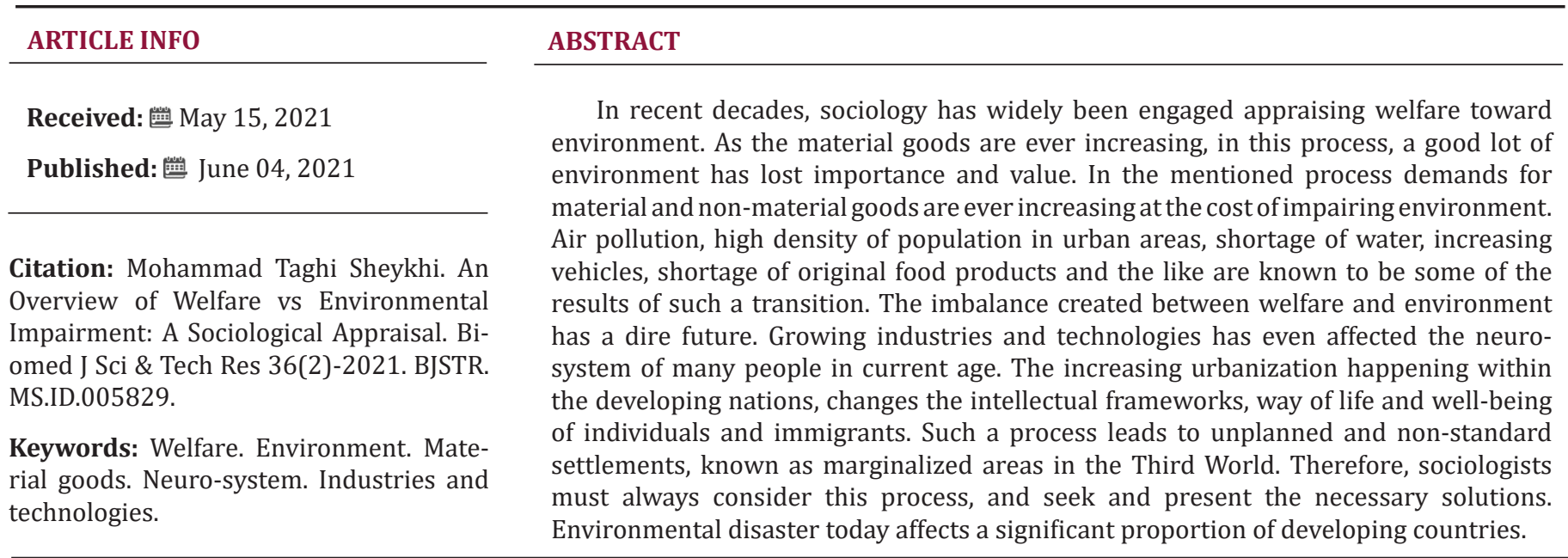

\section{Introduction}

Welfare as a type of government support is supposed to ensure that the members of a society should be able to meet their basic human needs including food and shelter Encyclopedia Britannica [1]. Welfare usually includes social insurance, pension systems and the like David [2]. The first welfare state was introduced by Bismarck in Germany in 1889. It was a point of reference for other countries in the Western world. On the other hand, environmental impairment is used to indicate the direct physical, chemical and biological factors impacting a person WHO [3]. Environmental exposures have been estimated to lead to 4.9 million deaths $(8.7 \%$ of all deaths), and 86 million (5.7\%) of disability-adjusted life years at global level Press-Ustinov A, et al. [4]. However, environmental impairment causes the degradation of the environment through the depletion of resources including air, water, and soil. Such a situation is observed in a great number of countries in the developing world. In addition, such an impairment includes destruction of ecosystems, habitats, wildlife extinction and many more. However, by 2050 , when the world population will have surpassed 10 billion, there will be further major welfare problems, especially of water and food kinds with special reference to less developed countries WPDS [5].

Environmental degradation involves the degradation of the environment through the depletion of resources such as air, water, and soil. Developing countries today face a continuing decline in their environment. Polluted air, depletion of water resources, and soil degradation for agricultural activities are common in developing countries. This in itself has reduced the utilization of various resources in such countries. Also, environmental degradation has included the destruction of ecosystems, habitats, wildlife extinction and many cases of pollution. Therefore, these countries should always put the improvement of their environment on the planning agenda, otherwise the overall efficiency of society will be jeopardized. Population itself has a great impact on how the environment. Access to advanced technologies, growing factories and industries, increasing the number of vehicles and other related technologies themselves affect the quality of the environment in various ways. Hence, developing countries face this scenario to a large extent. 


\section{Method of Research}

Methodology used in the present article is of qualitative type. In that, various paradigms have been used to find out about the facts regarding pandemics during the history. Qualitative research usually studies people, events, or areas in their natural settings. In finding facts for the research, the researcher engaged in careful data collection and thoughtful analysis of what was relevant. In the documentary research applied for the present research, printed and written materials were widely regarded. The research was performed as a qualitative library-type in which the researcher had to refer to the relevant and related sources. In the current research, various documents were thoroughly investigated, and the needful inferences were made. The data fed by the investigator in the present article is hopefully reliable. Though literature on pandemics is very limited, yet the author tried to investigate many different resources in order to elicit the necessary information to build up the text.

\section{Urbanization Flow}

Research on urbanization flows is mainly focused on urban areas, especially in temperate areas of relatively rich countries Gao [6]. The phenomenon of urbanization started mainly from industrialized countries and followed the process of industrialization. In this movement, a significant share of the rural population turned to cities in pursuit of industrial activities. For example, cities such as London, Birmingham and the like in the UK have experienced urbanization earlier than the rest of the world. Urbanization following the adaptation of modernism and industrialization gradually spread to other parts of the world. This movement within developing countries has been largely unbalanced and has left its own challenges and weaknesses. Most of the effects of urbanization are on developing communities, which are experiencing high population growth. This is why the greatest environmental degradation can be seen today in developing countries; That is, places that face both a natural increase in population (offspring) and a large number of immigrants. Hence, urbanization in developing countries must always be reconsidered Meanwhile, industrialized countries are facing both a natural decline in population and an influx of migrants from rural areas. Under such circumstances, these countries are less vulnerable to environmental degradation. The contradictions themselves arise during the urbanization of high-income and low-income countries Booth [7].

Cultural contexts and how economic development, industrialization, low monitoring of industrialization and the like, have led to many challenges and weaknesses in the environment. This situation is observed today in many developing countries, including China, India, and the like. Urbanization creates valuable ecosystem services, including heat, flood control, and recreational and tourist spots Meyer [8]. Urbanization must always consider the above infrastructure facilities and invest and manage on them. Developing countries are always facing the phenomenon of urbanization. The transfer of population from smaller to larger areas, or urbanization itself, changes the intellectual frameworks and way of life and well-being of individuals and immigrants; That is, the process that requires the investment of unplanned and non-standard settlements, known as marginalized areas in the Third World, is generally common in developing societies. As large numbers of people flock to urban areas uncontrollably and unrestrainedly, marginalization and non-standard places increase, a phenomenon that is itself the source of many deviations in a given society. Sociologists, therefore, must always consider this process, and seek and present the necessary solutions. Such settlements in low-income, low-income economies generally do not have access to safe water and sanitation. Because the rate of building the necessary infrastructure is lower than urban development Corcoran [9]. The ongoing flow of such urbanization poses many environmental threats.

Following the development of urbanization, the oversight of the Environment Organization and related agencies should continue actively. Reuse of polluted urban waters in agricultural sectors leads to a variety of microbial, viral, and similar diseases. Many urban waterways are polluted in various ways, and the agricultural sector is inevitably using these waters. Even today, many developing countries use wastewater sources for agriculture or crop boosting, which ultimately causes a variety of pollutants and diseases. The developing world today finds itself largely powerless against this dilemma. In the face of increasing population and density in urban areas, and in the absence of industrial wastewater in such countries, disposable water is not recycled and treated, and as a result, such resources are inevitably used in agriculture. The result of such a process is many diseases and infections in countries, especially in African countries. Lack of safe water and its infrastructure has largely led to a decline in welfare and facilities. In such circumstances, while the environment is objectively polluted, water resources in a non-objective form are also highly polluted and harmful. Therefore, organizations such as municipalities, environmental organizations, and ministries such as agriculture and the like should always have more control over such communications and interactions in order to promote health in their communities. Many Third World countries today face this dilemma, which results in many threats and eventually diseases.

Also, storing water in the suburbs and urban areas for use in water shortages has caused the spread of insects and other harmful pests for urban population Angel, et al. [10]. Many of these points are exposed to all kinds of pollution and disorders caused by pests of water resources in the conditions of water storage in the mentioned reservoirs, and ultimately the health of the members of 
a community is endangered. The environmental dimension implies that the depletion of resources and environmental degradation in less developed countries should be managed in such a way that the issue of insufficient energy and carbon monoxide emissions from fuel is not revealed in the industrial world and the Eastern world. Sustainable development indicates that resources should be exploited in such a way that in addition to the proper use of resources and products by the present generations, later generations will also be able to exploit and use resources. Today, many less developed countries pay less attention to the agricultural sector under the influence of various factors, and as a result, pursue living in cities and working in the industrial and service sectors; It is a process that affects the environment itself in various ways. This in itself has created overt and covert challenges for less developed societies. Weak environmental management has created an environmental crisis in Third World cities. Many today They produce carbon monoxide and the like. At the same time, such cities are gradually losing their green space.

And turn such spaces into residential places, industrial and office spaces (workshops), etc .; That is, a situation that poses many dangers to a healthy environment. These weaknesses need to be prevented and treated. One of the recommended ways is to register the population and monitor various migrations from smaller rural and urban areas to large cities. Reviving and prioritizing the agricultural sector can profoundly and positively affect the position of Third World countries. A kind of sustainable development management is needed to treat urban management in the Third World. Applying reasonable and comprehensive development in its forward-looking form can cure many environmental weaknesses. In this case, the health of human beings and society are both guaranteed as much as possible. In general, environmental issues should serve as an integral part of developing world politics.

\section{Urban Environmental Degradation}

Many researchers believe that in the context of economic development, environmental degradation first appears, and then gradually decreases. Economic development in which machinery and industrial units are used, to a large extent, causes the degradation of the environment. Generally, and gradually, industrial units manufacture and use catalysts, thereby preserving their environment as much as possible. This has already happened to industrialized countries. Industrialized nations have largely been able to protect their environment by controlling their populations on the one hand and conserving natural resources on the other. This issue is facing the developing countries today. This means that these countries, following the implementation of their development plans, have faced widespread urbanization, a phenomenon that has largely caused the destruction and pollution of the environment. The Kuznets environmental curve is based on a positive hypothesis that eliminates the growing development and establishment of poverty trade relations between increasing proportions of the population. Industrial and economic development, in which a larger share of the population is employed, and during which an increasing trend of income takes place, leads to a reduction in poverty.

Kuznets is also optimistic in this regard, emphasizing the eradication of poverty following industrial development. Today, many developing countries are in the process of facing environmental challenges. Hence, environmental disaster or challenge today affects a significant proportion of developing countries. In practice and in the context of the development of development strategies and trade relations in developing countries, since this action is mainly done to enrich the capitalists, it itself increases economic inequality Beckerman, et a l. $[11,12]$, and as a result a significant portion of the population is prevented from achieving the development that has taken place. It has become a failure and a lot of social and environmental damage. For example, urban sprawl has led to environmental degradation, transportation challenges, and many other harms. Cities themselves are absorbing more than two-thirds of the total population growth. Such a situation is widespread in the developing world. The constant migration of villagers to cities, especially in developing countries, has created such a phenomenon; That is, what acts as an anti-development factor. Today, such a situation is emerging in a pervasive and destructive form on the continent of Africa and its urban areas. Asian countries have been facing this phenomenon for years. China, for example, has grown its urban population by about 20 percent over the past two decades as its industrial development; It is a phenomenon that has threatened and destroyed the environment in various ways.

Many of the city's water resources, rivers and natural spaces have been unbearably degraded and polluted. This trend is current and probable for many other Asian countries. Under such circumstances, about 1.9 billion people occupied the urban areas of these countries until 2000. This trend has continued extensively since that year. This move has caused the world's population, including the developing world, to be more urban than rural. In addition to the environmental effects, this situation has led to a shortage of agricultural products and foodstuffs; That is, a phenomenon that has upset the balance of food supply and demand, in contrast to rising prices and economic inflation. The environment and the like should always have more control over the flow of such rivers. In addition to the pollution of these waters, the excessive use of motor vehicles has an effective role in polluting the environment. In a state of poor welfare, the people of Delhi are constantly and regularly facing water shortages. Also, the people of this city have to use the untreated water of Yamuna or Jamna river McMichael [13]. Existence of large population in such cities causes the emergence of this phenomenon. In such a situation, governments and the health system should exercise more control over the use of water resources and provide water-subsidized assistance to the population on an ongoing basis as needed. 


\section{Urbanization and Development}

Most developing countries are experiencing rapid urbanization, which in turn is associated with industrialization and service development. Following the process of globalization and the convergence of many global values, the process of urbanization has also occurred in some way or at a rapid pace over the past 70 years. Although this is done for the purpose of development, it itself has devastating effects on the health of the people of those communities. Many developing countries today face this dilemma. The result of such a movement is many diseases among different segments of the population in these areas. Therefore, and according to the recommendations of the United Nations, monitoring water, river water quality and preventing the entry of sewage into river channels, can to a large extent ensure better health for citizens. Countries like India, China and the like in Asia face such challenges. The pollution is easily visible in the Yamuna or Jamna River in Delhi. The river also receives 20 million liters of industrial waste and effluent annually. Population growth, the abundance of industrial workshops and products, domestic effluents and the like all make up 20 million liters of effluent. On the other hand, population density in such rivers creates a lot of vulnerability among the population. Hence, environmental degradation in such places and spaces seems inevitable. Organizations such as municipalities and environmental organizations have a valuable role to play in preventing this crisis. Therefore, these countries can prevent the emergence of urban crises fairly in all urban and rural areas by pursuing decentralized policies and distributing facilities, and thus create greater prosperity.

\section{Environmental Health and Well-Being}

Environmental health as a branch of public health and health includes natural and man-made aspects of the environment that affect human health and well-being. Environmental science itself, which deals with environmental health, ultimately pursues human health and well-being. Protecting and monitoring various aspects of the environment as a guarantor of human health plays a role. Environmental health was defined in 1999 by the World Health Organization as "the very aspects of human health and disease that are determined by environmental factors." It refers to the evaluation and control of factors that theoretically and practically and in a potential way affect health. Environmental health includes the direct effects of chemicals, and other related factors that physically (physically), psychologically, socially, and culturally affect housing, urban development, land use, and transportation, and thus the well-being of the species. Endangers human beings Novice [14]. Environmental health services always encourage environmental policies through which environmental indicators are promoted and taken healthy forms by human behaviors WHO $[15,16]$. Environmental health also examines air quality, disaster preparedness, climate change, environmental racism (in which some social groups are exposed to environmental disasters), food health, waste management, healthy housing and marginalization monitoring, planning, operation.

It deals with land, hospital waste, noise pollution, drinking water sanitation, control and eradication of banana and insect organisms, consumer products and the like. In general, environmental health is achieved by emphasizing the above, and it is in such circumstances that public welfare is ensured in a society. Developed societies have been addressing this issue for years and have subsequently provided greater well-being and health to their societies. Many countries have taken effective steps in this field by specializing in environmental sciences, including environmental engineering, through which they have been able to prevent many diseases among different age groups. Thus, health and well-being have developed in the above societies and consequently life expectancy has generally increased in those societies.

\section{Conclusion}

Sociology believes that economic development in which machinery and industrial units are used to a large extent causes the impairment of the environment. Industrial units generally manufacture and use catalysts to preserve the environment as much as they can. This has already happened to industrialized countries. Such nations have largely been able to protect their environment by controlling their populations on the one hand and conserving natural resources on the other hand. Environmental health if achieved, circumstances are framed and public we fare is ensured in a society. Many countries have taken effective steps in the field in order to access further welfare. For that, specializing in environmental sciences including environmental engineering is recommended.

\section{References}

1. (2016) Social Welfare Program, Encyclopedia Britannica.

2. David S (2007) International Human Rights Law: An Introduction, University of Pennsylvania Press.

3. (2015) World Health Organization.

4. Ustinov A (2011) Scholarly Articles for Press.

5. (2020) World Population Data Sheet, Population Reference Bureau, Washington DC.

6. Gao JB, Qian Wu, Qingliang Li, Jun Ma, Qiufang Xu, et al. (2013) Preliminary results from monitoring of Streams Nitrogen Concentrations, Denitrification, and Nitrification Potentials in an Urbanizing Watershed in Xiamen, Southeast China. Internationals Journal of Sustainable Development and World Ecology 20: 223-230.

7. Booth DB (2016) Global Perspectives on Urban Stream Syndrome. Freshwater Sciences 35: 411-420.

8. Meyer JL (2005) Stream eco-system function in urbanizing landscapes, Journal of North American Benthological Society 24(3): 602-612. 
9. Corcoran E, C Nellemann, E Baker, R Bos, D Osborn, et al. (2010) Sick water? The central role of wastewater management in sustainable development. A rapid response assessment, UN-HABITAT, GRID Arendal, New York

10. Angle B, V Joshi (2008) Distribution and seasonality of vertically transmitted dengue viruses in Aedes mosquitos in arid and sami arid areas of Rajasthan, India. Journal of Vector Borne Diseases 45(1): 56-59.

11. Beckerman W (1992) Economic growth and the environment: whose growth? whose environment? World development 20: 481-496.

ISSN: 2574-1241

DOI: $10.26717 /$ BJSTR.2021.36.005829

Mohammad Taghi Sheykhi. Biomed J Sci \& Tech Res

(C) (P) This work is licensed under Creative

Submission Link: https://biomedres.us/submit-manuscript.php
12. Tobey J (1989) Economic development and environmental management in the Third World, Habitat International 13: 125-135.

13. McMichael AJ (2000) The urban environment and health in a world of increasing globalization: Issues for developing countries. Bulletin of the World Health Organization 78(9): 1117-1126.

14. Novice R (1999) Overview of the Environment and Health in Europe, World Health Organization: New York.

15. (2015) World Health Organization. Health topics: Environmental Health.

16. (2019) Social Security History.

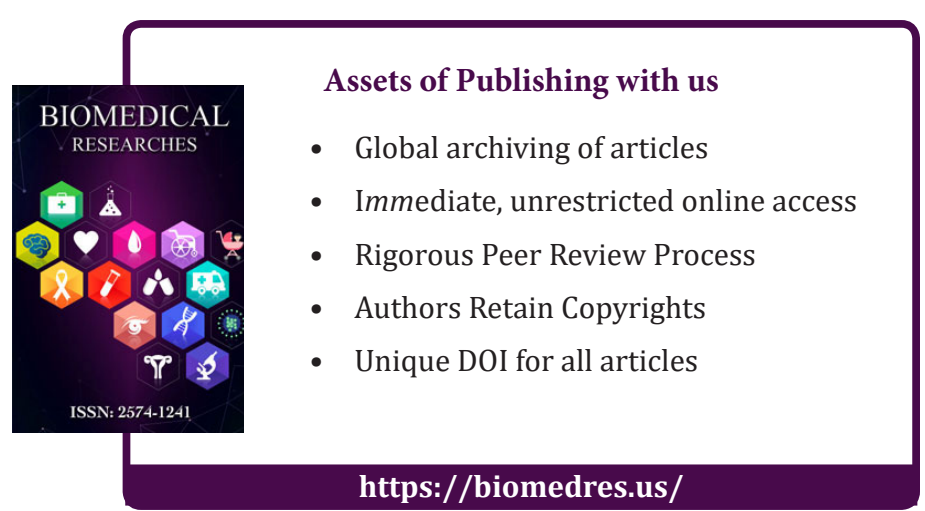

